\title{
Implementation of Breed-Specific Traits for a Local Sheep Breed
}

\author{
Jonas Schäler ${ }^{*}$, Georg Thaller ${ }^{1}$, Dirk Hinrichs² \\ ${ }^{1}$ Institute of Animal Breeding and Husbandry, Christian-Albrechts-University, Kiel, Germany \\ ${ }^{2}$ Department of Animal Breeding, University of Kassel, Kassel, Germany \\ Email: *jschaeler@tierzucht.uni-kiel.de
}

How to cite this paper: Schäler, J., Thaller, G. and Hinrichs, D. (2018) Implementation of Breed-Specific Traits for a Local Sheep Breed. Agricultural Sciences, 9, 958-973. https://doi.org/10.4236/as.2018.98067

Received: July 20, 2018

Accepted: August 14, 2018

Published: August 17, 2018

Copyright (c) 2018 by authors and Scientific Research Publishing Inc. This work is licensed under the Creative Commons Attribution International License (CC BY 4.0).

http://creativecommons.org/licenses/by/4.0/

\section{(c) (†) Open Access}

\begin{abstract}
In recent decades, a considerable number of local breeds have been replaced by high-yielding breeds for reasons of profitability. Many local breeds are now threatened by extinction and the loss of their native genetic diversity. The need to conserve breeds and their genetic diversity has a major importance due to the necessity for genetic change within and between populations. Novel approaches have to be explored and extended to maintain this genetic diversity. The aim of this study was the identification and implementation of breed-specific traits for a small, local sheep breed in northern Germany. The data comprised pedigree information, estimated breeding values (EBVs) of several conventional traits, and phenotypic information from a field experiment for two novel traits: 1) average daily gain under extensive circumstances $\left(\mathrm{ADG}_{\mathrm{E}}\right)$ and 2) ultrasonic measurements of muscle-fat ratio (UMFR). The experimental design included a dataset of 47 progeny from 14 pure-bred rams of German White-Headed Mutton (GWM). The methodical approach was divided into four parts: 1) the analysis of the breeding programme, 2) the identification of breed-specific traits, 3) the estimation and correlation of novel breeding values, and 4) the consequences of implementing these novel traits. Genetic parameters and correlations were conducted by applying linear mixed models. The estimates for the heritability (repeatability) were between 0.70 and 0.83 (0.42 and 0.46 ). The genetic correlation was positive (0.61) and in accordance with the phenotypic correlation (0.62). Average daily gain under intensive circumstances $\left(\mathrm{ADG}_{\mathrm{I}}\right)$ was moderately positive correlated with muscularity (0.60), as opposed to $\mathrm{ADG}_{\mathrm{E}}$, which was moderately negative correlated with muscularity $(-0.68)$. The $\mathrm{EBV}$ of $\mathrm{ADG}_{\mathrm{E}}$ was also moderately positive correlated with UMFR (0.64). Genetic response for $\mathrm{ADG}_{\mathrm{E}}$ enhanced to values of $481.09 \mathrm{~g} /$ day, $639.97 \mathrm{~g} / \mathrm{day},>700 \mathrm{~g} /$ day and $>850 \mathrm{~g} /$ day for different selection intensity scenarios. Corresponding rates of inbreeding were $1.4 \%, 2.7 \%, 5.1 \%$, and $7.9 \%$ after 10 years of selection. Genetic response for
\end{abstract}


UMFR increased to $0.92,1.34,2.41$, and $>2.75$, whereas remaining rates of inbreeding increased to $1.1 \%, 2.2 \%, 5.1 \%$, and $7.9 \% . \mathrm{ADG}_{\mathrm{I}}$ and $\mathrm{ADG}_{\mathrm{E}}$ were tendentially negatively correlated $(-0.11)$, which strengthen the assumption of a biased $A D G_{I}$. $A D G_{E}$ has a positive influence on meat-quality aspects (UMFR). Optimal use of reference sires with predefined selection intensity achieves genetic response for $\mathrm{ADG}_{\mathrm{E}}$ and UMFR with simultaneously acceptable rates of inbreeding.

\section{Keywords}

EBV, Genetic Gain, Local Sheep Breed, New Phenotypes, Novel Traits, Selection Intensity

\section{Introduction}

The domestication of livestock species has created an enormous variety of breeds due to a long history of migrations, selection, and adaptation [1]. During the last few centuries, many well-defined breeds have peaked in numbers and have been used for a variety of purposes with different levels of performance depending on demographic and local environments. In recent decades, however, the reproductive technologies of artificial insemination and embryo transfer have become more widespread [2], and have facilitated the dissemination of genetic material. As a consequence, selection programmes have become more efficient and have accelerated the genetic gain in a small number of breeds. These high-yielding breeds have replaced many local breeds, which has resulted in a high rate of loss of local breeds due to extinction [3]. Thus, many populations of local breeds have dangerously decreased in number and are even threatened by extinction [4] [5] [6]. According to Boettcher et al. [7], there exists a wide agreement on the need to conserve breeds and their genetic diversity due to the necessity for genetic change within a population. In addition, local breeds with their native genetic diversity allow for the selection of special traits to increase productivity, competitiveness, and to adapt to changing environmental conditions. Different approaches and considerations were discussed by Meuwissen [3] for the purpose of breed conservation. These methods consisted of aspects of optimum contribution selection [8] [9], integrating life and cryoconservation schemes [10] [11], rotational breeding schemes [12], and the introduction of novel traits from conserved populations into commercial breeding populations [13] [14]. The latter approach implies that traits from conserved breeds can be introduced into commercial breeds by introgression and genomic selection. For most local breeds, however, genomic selection is not implemented due to the small population sizes or costs. Thus, breeding progress is still based on recording phenotypic information. However, most local breeds are implemented into conventional breeding programmes, where the specific traits (e.g. fertility, meat quality, milk 
ingredients, and robustness) of local breeds attract no interest and may even be lost due to undefined negative correlations with positively selected conventional traits. Additionally, certain traits (e.g. disease resistance) of local breeds are not identified or phenotypically recorded in conventional breeding programmes. Thus, usage, conservation, and breeder's impact regarding these traits are complicated. It should be of major importance to identify and conserve these unique and worthwhile traits from conserved local breeds as long as they still exist.

The aim of the present study was to identify and implement breed-specific traits for a small, local sheep breed in Germany. Therefore, estimated breeding values (EBVs) for novel traits were computed based on collected phenotypic information from a field experiment. Further, correlations between novel and conventional EBVs were investigated and benefits of implementing these novel traits were clarified.

\section{Materials and Methods}

\section{Animals and Phenotypes}

For an effective recording of phenotypes and optimally statistical computation of novel EBVs, preliminary considerations were carried out with regard to the experimental design dependent on the possibilities of local farmers and their local breed. Data comprised pedigree information, EBVs for several conventional traits, and phenotypic information on average daily gain under extensive circumstances $\left(\mathrm{ADG}_{\mathrm{E}}\right)$ and quantitative ultrasonic (QUS) measurements of muscle-fat ratio (UMFR) for 47 progeny from 14 pure-bred rams (reference sires) of German White-Headed Mutton (GWM), born between 2010 and 2014. Pedigree information was provided by LKV SH (Landeskontrollverband Schleswig-Holstein e.V., Kiel, Germany). However, EBVs for conventional traits and phenotypic data on $\mathrm{ADG}_{\mathrm{E}}$ and UMFR were provided by LV SH SZZ (Landesverband Schleswig-Holsteinischer Schaf-und Ziegenzüchter e.V., Kiel, Germany).

Phenotypic data was collected and measured during a field experiment on one standardized farm, where 47 pure-bred male progeny of 14 GWM reference sires were fattened based on extensive feed without concentrates during a trial period of 100 days. During the field study ethical considerations of animal welfare along the lines of Putman [15] were claimed. The animals had an average age of 99.4 days and were divided into two groups depending on their date of birth. One group included 24 animals born in the first half of January 2016. The other group contained 23 animals born during the second half of the month. The data collection consisted of measuring the rams' weight at six different times at regular intervals over the trial period and the QUS measurements of muscle and the QUS measurements of fat depth separately at the end of the experiment. The trait of $\mathrm{ADG}_{\mathrm{E}}$ resulted from dividing the average weight gain, deducting the general birth weight of approximately $4.5 \mathrm{Kg}$, by the experimental time of the trial period per animal. The trait of UMFR was computed by dividing the QUS measurements of muscle by the QUS measurements of fat depth. Observed 
phenotypes for the trait of $\mathrm{ADG}_{\mathrm{E}}$ ranged between 373.0 and $243.3 \mathrm{~g} /$ day (Table 1). However, phenotypic observations for the trait of UMFR were recorded between the maximum of 2.78 and the minimum of 1.32 (Table 1).

The inbreeding coefficients $(F)$ were estimated with the function "pedIn breeding" from the "optiSel" R-package [16], whereas the rates of inbreeding were calculated for each year as $\Delta F_{i}=\left(F_{i}-F_{i-1}\right) /\left(1-F_{i-1}\right)$. The rate of inbreeding between year $i$ and $j\left(\Delta F_{i-j}\right)$ was computed by the average of annual inbreeding rates [17]. The additive genetic relationship matrix was estimated with the function "make A" from R-package "optiSel” [16].

\subsection{Analysis of the Breeding Programme}

Important information regarding the breeding programme was collected from the breeding organisation on demand. The breeding programme was analysed by identifying breeding goals and conventional traits with their relative weights and analysing their influence on total merit index (TMI). The breeding goal for GWM is defined as a robust, muscled, and well-growing mutton, which is well-adapted to grazing in damp and maritime climates and various ground conditions. The conventional TMI included the three traits of average daily gain under intensive circumstances $\left(\mathrm{ADG}_{\mathrm{I}}\right)$, muscularity (MUSC), and wool (WOL) with consistent relative weights of 0.33 for each trait.

Table 1. Observation averages of German White-Headed Mutton (GWM) reference sire's progeny for the novel traits of average daily gain under extensive circumstances $\left(\mathrm{ADG}_{\mathrm{E}}\right)$ and ultrasonic muscle-fat ratio (UMFR).

\begin{tabular}{cccc}
\hline \multirow{2}{*}{ Reference sire } & \multicolumn{2}{c}{ Observations for novel traits $^{\mathrm{a}}$} \\
\cline { 2 - 4 } 1 & ID 1 & $\mathrm{ADG}_{\mathrm{E}}(\mathrm{g} /$ day $)$ & UMFR \\
\hline 2 & ID 2 & 309.2 & 1.74 \\
3 & ID 3 & 333.0 & 1.53 \\
4 & ID 4 & 319.0 & 1.53 \\
5 & ID 5 & 329.0 & 1.89 \\
6 & ID 6 & 317.0 & 1.40 \\
7 & ID 7 & 292.4 & 1.32 \\
8 & ID 8 & 347.0 & 1.67 \\
9 & ID 9 & 371.0 & 2.78 \\
10 & ID 10 & 287.0 & 1.65 \\
11 & ID 11 & 335.0 & 1.40 \\
12 & ID 12 & 288.4 & 1.36 \\
13 & ID 13 & 243.3 & 1.39 \\
14 & ID 14 & 314.0 & 1.59 \\
\hline
\end{tabular}

${ }^{\mathrm{a}} \mathrm{ADG}_{\mathrm{E}}=$ average daily gain under extensive circumstances; UMFR = ultrasonic muscle-fat ratio. 


\subsection{Identification of Breed-Specific Traits}

The breed and its breeding history were analysed to identify special and valuable traits. A comprehensive literature review was carried out and, in addition, face to face interviews with farmers and staff of the breeding organisation were conducted to emphasise breed-specific traits. The main purpose of the GWM breed is landscape conservation on the dykes of the northern coasts of Germany. Thereby, their job with their browsing is it to make the dyke slip-proof, densify the ground, and to ensure against flooding. In general, the animals were kept outside on the dykes with their progeny the whole year and only received extensive feed without supplemented concentrates. However, when young rams became licensed for breeding purposes, farmers began to fatten their rams additionally with supplements to increase weights in order to obtain a higher breeder valuation later. Thus, valuation results for GWM rams were erroneously assumed to be correct for the trait of conventional ADG related to the constant feed environment. The trait of conventional ADG for GWM rams is biased, which has a major impact on the carcass value of the lambs. Currently, the main source of income from the GWM breed besides landscape conservation is to submit the lambs for slaughter. For the local sheep breed, a special feature of ADG based on extensive feed intake $\left(\mathrm{ADG}_{\mathrm{E}}\right)$ was assumed due to the breeding history, demographic circumstances of husbandry, and economic value of this trait. In addition, it was assumed that the fattening period under extensive circumstances had an impact on the muscle and fat depth ratio (UMFR), which is an important meat-quality indicator.

\subsection{Estimation and Correlation of Novel Breeding Values}

To compute novel EBVs, linear mixed models (LMM) were applied using the R-package "asreml" from Butler et al. [18]. The LMM can be written as

$$
y=X b+Z_{A} a+\sum_{k} Z_{k} u_{k}+e
$$

where $y$ denotes the $n$-vector of phenotypic values, $b$ is the vector of fixed effects, $a$ is the vector of random additive genetic effects of the animal distributed as $a \sim N\left(0, \sigma_{a}^{2} A\right)$, where $\sigma_{a}^{2}$ is the additive genetic variance and $A$ is the additive relationship matrix. Vector $u_{k}$ of independent random effects has distribution $u_{k} \sim N\left(0, \sigma_{u_{k}}^{2} I\right)$ and $e$ is the $n$-vector of independent residual errors with $e \sim N\left(0, \sigma_{e}^{2} I\right)$. Matrices $X, Z_{A}$, and $Z$ are design matrices associating observations with the appropriate combination of effects. Fixed and random effects of sire, dam, sex, date of birth, and breeder were tested for significance using the R-package "asremlPlus" from Brien [19]. The statistical analyses were performed simultaneously in a bivariate analysis for each trait in order to estimate the repeatability $(t)$ and the heritability $\left(h^{2}\right)$ for these traits. The repeatability following Lessells and Boag [20] was computed as

$$
t=\frac{\sigma_{a}^{2}+\sum_{k} \sigma_{u_{k}}^{2}}{\sigma_{a}^{2}+\sum_{k} \sigma_{u_{k}}^{2}+\sigma_{e}^{2}}
$$


and the heritability following Falconer and Mackay [21] was calculated as

$$
h^{2}=\frac{\sigma_{a}^{2}}{\sigma_{a}^{2}+\sum_{k} \sigma_{u_{k}}^{2}+\sigma_{e}^{2}}
$$

The estimation of genetic $\left(\hat{r}_{G}\right)$ and phenotypic $\left(\hat{r}_{P}\right)$ correlations following Falconer and Mackay [21] between the traits were also conducted within the pairwise bivariate analysis by usage of the LMM. The genetic correlation was calculated as

$$
\hat{r}_{G(X, Y)}=\frac{\operatorname{cov}\left(\sigma_{a(X)}^{2} \sigma_{a(Y)}^{2}\right)}{\sqrt{\sigma_{a(X)}^{2} \sigma_{a(Y)}^{2}}}
$$

and the phenotypic correlation was computed as

$$
\hat{r}_{P(X, Y)}=\frac{\operatorname{cov}\left(\sigma_{a(X)}^{2} \sigma_{a(Y)}^{2}\right)+\operatorname{cov}\left(\sum_{k}\left(\sigma_{u_{k}}^{2}\right)_{(X)} \sum_{k}\left(\sigma_{u_{k}}^{2}\right)_{(Y)}\right)}{\sqrt{\sigma_{a(X)}^{2} \sigma_{a(Y)}^{2}}+\sqrt{\sum_{k}\left(\sigma_{u_{k}}^{2}\right)_{(X)} \sum_{k}\left(\sigma_{u_{k}}^{2}\right)_{(Y)}}}
$$

where $X$ and $Y$ denote distinct traits.

Correlations between novel and conventional EBVs were estimated with the "cor.test" function from the R-package "stats" [22].

\subsection{Implementation of Breed-Specific Traits}

Selection on breed-specific traits was carried out for 10 years with genetic evaluation of all animals once a year. The genetic evaluation was based on the estimation of genetic response with the formula from Rendel and Robertson [23], calculated as

$$
\Delta G=\frac{i * r_{B V} * \sigma_{A}}{L}
$$

where $i$ is the selection intensity, $r_{B V}$ is the correlation between true and estimated breeding value, $\sigma_{A}$ is the additive genetic standard deviation of the trait, and $L$ is the generation interval of the species or breed. Four scenarios with different $i$ were considered based on the selected proportions ( $\mathrm{p} \%$ ) of the reference sires. To translate $\mathrm{p} \%$ to the corresponding $i$, different tables were used from Falconer and Mackay [21]. First scenario had a p\% of 50 and was translated to an $i_{1}$ of 0.798 , which meant 7 out of 14 reference sires. Second, third, and fourth scenarios had different $\mathrm{p} \%$ of 36,21 , and 14 and were compiled to corresponding $i_{2}$ of $1.039, i_{3}$ of 1.372 , and $i_{4}$ of 1.590 , which implemented 5,3 , and 2 out of 14 reference sires. Correlation between true and estimated breeding value (accuracy of breeding value estimation) as well as the values for trait-specific $\sigma_{A}$ were calculated within the LMM. Average generation interval for ewes $\left(L_{e}\right)$ was defined as 3.5 years and the average generation interval for reference sires $\left(L_{s}\right)$ was considered as 2.7 years [17]. The true generation interval of $L$ is the average 
of both parameters and had a value of 3.1 computed as $L=\frac{L_{e}+L_{s}}{2}$. Reference sires were chosen based on their phenotypic measurements for the goal trait. Within a flock, 20 ewes were mated to one of the selected reference sires depending on different $i$-scenarios. For $i_{1}$ in total 7 flocks with each of them 20 ewes were mated with 7 different reference sires over 10 years. For $i_{2}, i_{3}$, and $i_{4}$ in total 5, 3, and 2 flocks with each of them 20 ewes were mated with 5, 3, and 2 different reference sires over 10 years. Average phenotypic measurements $\left(G_{i}\right)$ was obtained for selected reference sires in the $i$ th year and the annual rate of response between years $j$ and $i$ was computed as

$$
\Delta G_{i-j}=\left(G_{j}-G_{i}\right) /(j-i)
$$

where $j>i[17]$.

\section{Results}

The number of GWM herdbook animals tendentially declined until the year 2015. In 1970, the recording of the herd book started with a small number of animals and simultaneously the herdbook animals began to increase up to a maximum of approximately 830 recorded animals between 1988 and 1989. After this peak, GWM herd book livestock steadily decreased to a minimum of 167 individuals in 2015 (Figure $1(\mathrm{a})$ ). The rate of inbreeding $(\Delta F)$ was constant at a low level between 1970 and 1986. In 1987, $\Delta F$ increased from $0.07 \%$ to $0.7 \%$ till 2007. The time period between 2007 and 2015 showed a rapidly increased $\Delta F$ up to approximately $10 \%$ (Figure $1(\mathrm{~b})$ ). The $F$ of reference sires had an average value of $0.61 \%$, whereas 3 rams showed low coefficients between $0.78 \%$ and $1.56 \%$, and $1 \mathrm{ram}$ had a high inbreeding of $4.69 \%$ (Figure 2(a)). In total, nearly all reference sires revealed relatedness (Figure 2(b)). Reference sires ID 2, ID 3, ID 6, ID 7, ID 8, ID 10, ID 11, and ID 12 showed different levels of relatedness to one or more reference sires. Collected phenotypic observations for average daily gain under extensive circumstances and ultrasonic muscle-fat ratio (Table 1) were positively linearly related with a correlation of 0.62 (Figure 3 ).

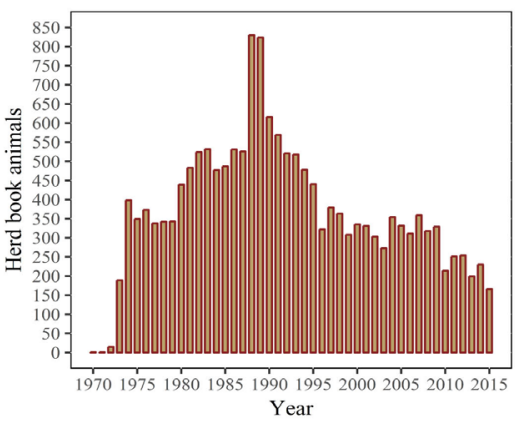

(a)

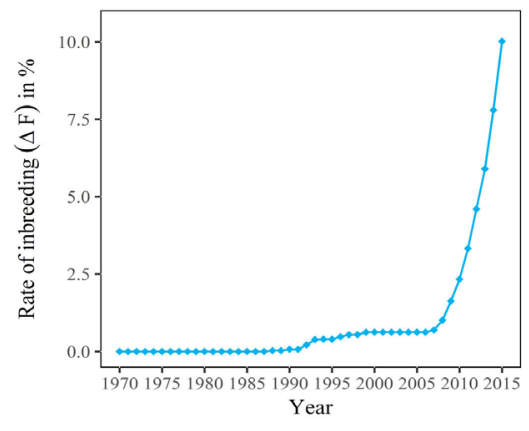

(b)

Figure 1. Indication of (a) Frequency of herd book animals and (b) Rates of inbreeding $(\Delta F)$ regarding past breed history of the German White-Headed Mutton (GWM). 


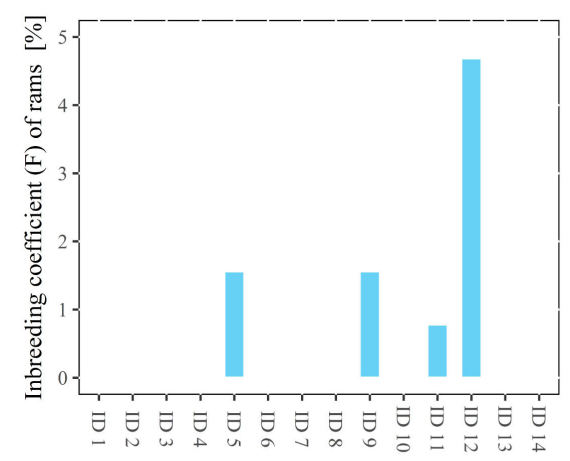

(a)

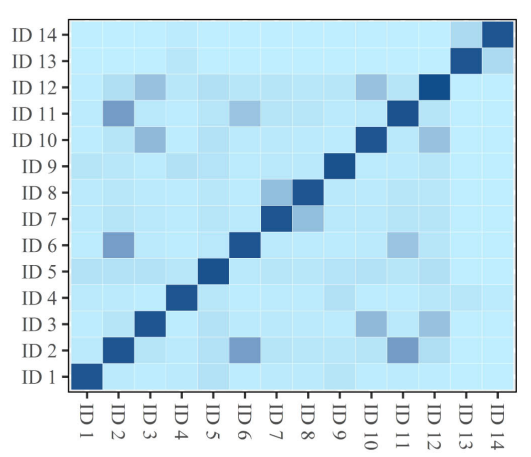

(b)

Figure 2. In (a) Estimated inbreeding coefficients $(F)$ and in (b) Corresponding additive genetic relationship matrix of reference sires.

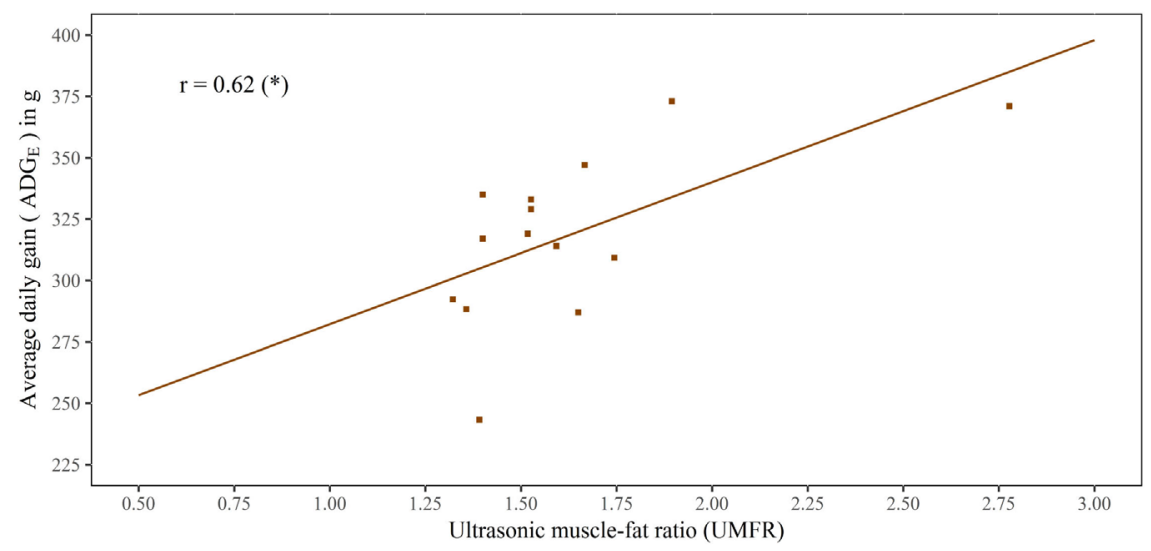

Figure 3. Phenotypic relation between average daily gain under extensive circumstances $\left(\mathrm{ADG}_{\mathrm{E}}\right)$ and ultrasonic muscle-fat ratio (UMFR).

\subsection{Estimation and Correlation of Novel Breeding Values}

The effects of sex and date of birth were significant $(\mathrm{p} \leq 0.001)$ for both traits, thus they were included as fixed effects in the models. However, the random effect of dam was included in the genetic analysis as a random effect in order to avoid an over-estimation of heritability, an under-estimation of maternal effects, and to increase the reliability. The repeatability for the trait $\mathrm{ADG}_{\mathrm{E}}$ was 0.42 and 0.46 for the trait of UMFR. The corresponding heritability was 0.70 for $\mathrm{ADG}_{\mathrm{E}}$ and 0.83 for UMFR (Table 2). Phenotypic and genetic correlations are positive between both traits with 0.62 and 0.61 (Table 3 ). The correlation between true and estimated breeding value $\left(r_{B V}\right)$ was fixed and had an accuracy of 0.725 for both traits. Investigated trait-specific parameters of $\sigma_{A}$ were $186.81 \mathrm{~g}$ for $\mathrm{ADG}_{\mathrm{E}}$ and 0.49 for UMFR. Correlations between novel and conventional EBVs are shown in Table 4. ADG was moderately positive correlated with MUSC (0.60), whereas $\mathrm{ADG}_{\mathrm{E}}$ was moderately negative correlated with MUSC (-0.68). The $\mathrm{EBV}$ of $\mathrm{ADG}_{\mathrm{E}}$ was also moderately positive correlated with the EBV of UMFR (0.64). Other correlations between EBVs were not statistically significant. 
Table 2. Results of bivariate analyses for heritability $\left(\hat{h}^{2}\right)$ and repeatability $(\hat{t})$ of average daily gain under extensive circumstances $\left(\mathrm{ADG}_{\mathrm{E}}\right)$ and ultrasonic muscle-fat ratio (UMFR) and standard errors (SE).

\begin{tabular}{|c|c|c|c|c|}
\hline \multirow{2}{*}{ Traits $^{\mathrm{a}}$} & \multicolumn{4}{|c|}{ Linear mixed model (LMM) } \\
\hline & Repeatability $\hat{t}$ & (SE) & Heritability $\hat{h}$ & $2(\mathrm{SE})$ \\
\hline $\mathrm{ADG}_{\mathrm{E}}$ & 0.42 & $(0.31)$ & 0.70 & $(0.95)$ \\
\hline UMFR & 0.46 & $(0.46)$ & 0.83 & (0.59) \\
\hline
\end{tabular}

${ }^{\mathrm{a}} \mathrm{ADG}_{\mathrm{E}}=$ average daily gain under extensive circumstances; $\mathrm{UMFR}=$ ultrasonic muscle-fat ratio.

Table 3. Results of bivariate analyses for phenotypic (above the diagonal) and genetic (below the diagonal) correlations $\left(\hat{r}_{G}\right.$ and $\hat{r}_{P}$ ) between average daily gain under extensive circumstances $\left(\mathrm{ADG}_{\mathrm{E}}\right)$ and ultrasonic muscle-fat ratio (UMFR) and standard errors (SE).

\begin{tabular}{ccc}
\hline Traits $^{\mathrm{a}}$ & $\mathrm{ADG}_{\mathrm{E}}$ & UMFR \\
\hline $\mathrm{ADG}_{\mathrm{E}}$ & - & $0.62(0.30)$ \\
UMFR & $0.61(0.29)$ & - \\
\hline
\end{tabular}

${ }^{\mathrm{a}} \mathrm{ADG}_{\mathrm{E}}=$ average daily gain under extensive circumstances; UMFR = ultrasonic muscle-fat ratio.

Table 4. Correlation between novel estimated breeding values (EBVs) of $\mathrm{ADG}_{\mathrm{E}}$ and UMFR and conventional EBVs of $\mathrm{ADG}_{\mathrm{I}}$, MUSC, and WOL.

\begin{tabular}{|c|c|c|c|c|c|}
\hline $\mathrm{EBV}^{\mathrm{a}}$ & $\mathrm{ADG}_{\mathrm{I}}$ & MUSC & WOL & $\mathrm{ADG}_{\mathrm{E}}$ & UMFR \\
\hline $\mathrm{ADG}_{\mathrm{I}}$ & 1 & $0.60\left(^{*}\right)$ & -0.12 (n.s.) & -0.11 (n.s.) & 0.04 (n.s.) \\
\hline MUSC & & 1 & 0.06 (n.s.) & $-0.68\left(^{* *}\right)$ & -0.31 (n.s.) \\
\hline WOL & & & 1 & -0.40 (n.s.) & -0.17 (n.s.) \\
\hline $\mathrm{ADG}_{\mathrm{E}}$ & & & & 1 & $\left.0.64{ }^{*}\right)$ \\
\hline UMFR & & & & & 1 \\
\hline
\end{tabular}

${ }^{a}$ Estimates were tested for statistical significance: $p$-value $\geq 0.05$ (n.s.), $<0.05\left({ }^{*}\right),<0.01\left({ }^{* *}\right),<0.001\left(^{* * *}\right)$; $\mathrm{ADG}_{\mathrm{I}}=$ average daily gain under intensive circumstances, $\mathrm{MUSC}=$ muscularity, $\mathrm{WOL}=$ wool, $\mathrm{ADG}_{\mathrm{E}}=\mathrm{av}-$ erage daily gain under extensive circumstances, UMFR = ultrasonic muscle-fat ratio.

\subsection{Implementation of Breed-Specific Traits}

Genetic response and corresponding $\Delta F$ were simulated for the implementation of the trait $\mathrm{ADG}_{\mathrm{E}}$ regarding different $i$-scenarios over 10 years of selection (Figure 4). Genetic response of $\mathrm{ADG}_{\mathrm{E}}$ increased with an increasing $i$. In total, genetic response enhanced from the average of $318.45 \mathrm{~g} /$ day to values of $481.09 \mathrm{~g} /$ day for $i_{1}$ and $639.97 \mathrm{~g} /$ day for $i_{2}$ after 10 years of selection. However, genetic response for $i_{3}$ and $i_{4}$ reached values $>700 \mathrm{~g} /$ day and $>850 \mathrm{~g} /$ day after 7 years of selection (Figure 4(a)). Corresponding $\Delta F$ decreased from an average $F$ of 2.22 at year 0 of selection to the first years of selection depending on different $i$, whereas $\Delta F$ started to increase rapidly with an increasing value of $i$ after some years of selection. After 10 years of selection, $\Delta F$ had values of $1.4 \%, 2.7 \%, 5.1 \%$, and $7.9 \%$ for $i_{1}, i_{2}, i_{3}$ and $i_{4}$ (Figure $4(\mathrm{~b})$ ). For UMFR the same simulations were performed and are shown in Figure 5. Genetic response increased from an average of 0.49 


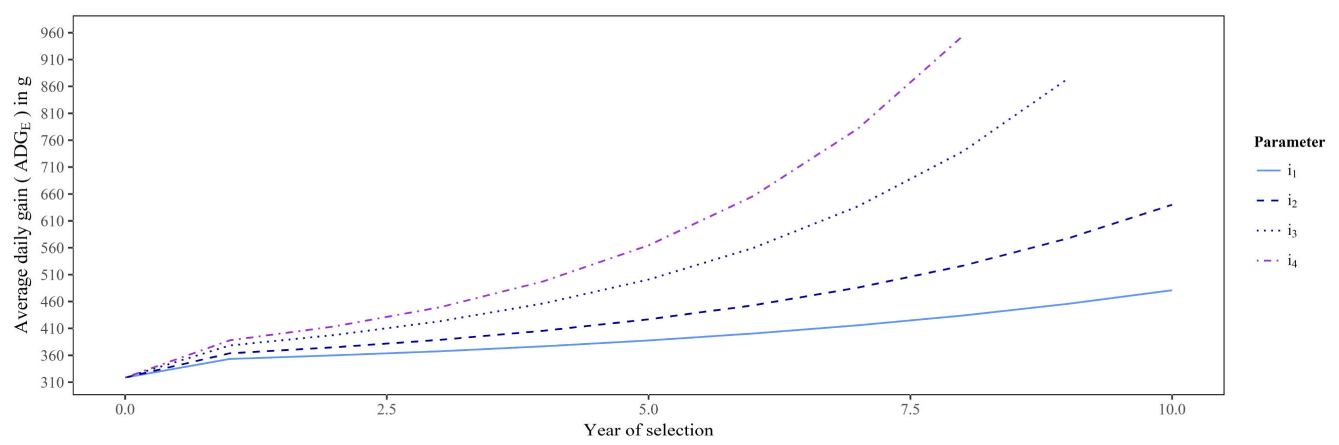

(a)

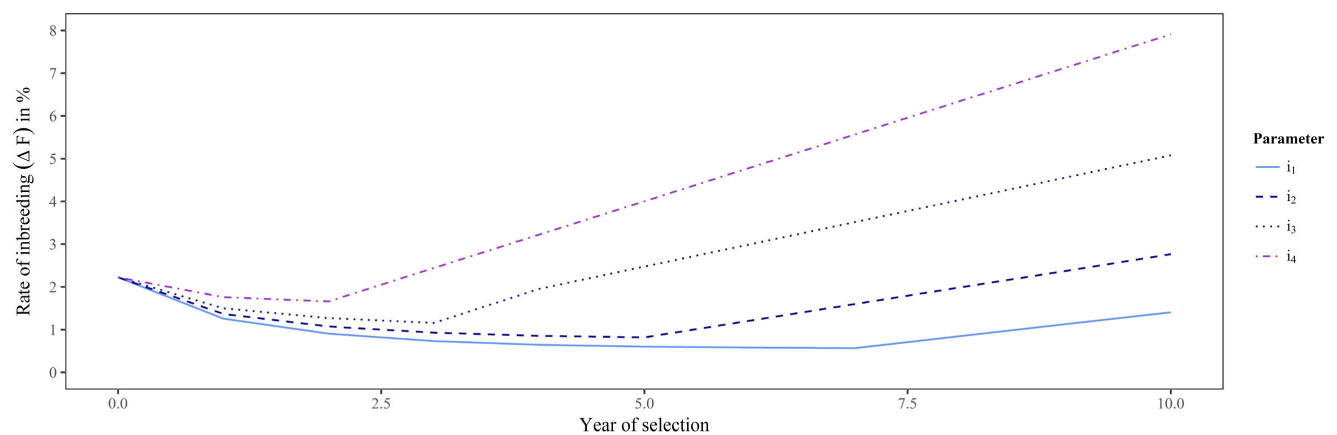

(b)

Figure 4. In (a) Change in genetic gain for average daily gain under extensive circumstances $\left(\mathrm{ADG}_{\mathrm{E}}\right)$ and in (b) Corresponding rates of inbreeding $(\Delta F)$ over years with different selection intensities $(i)$.

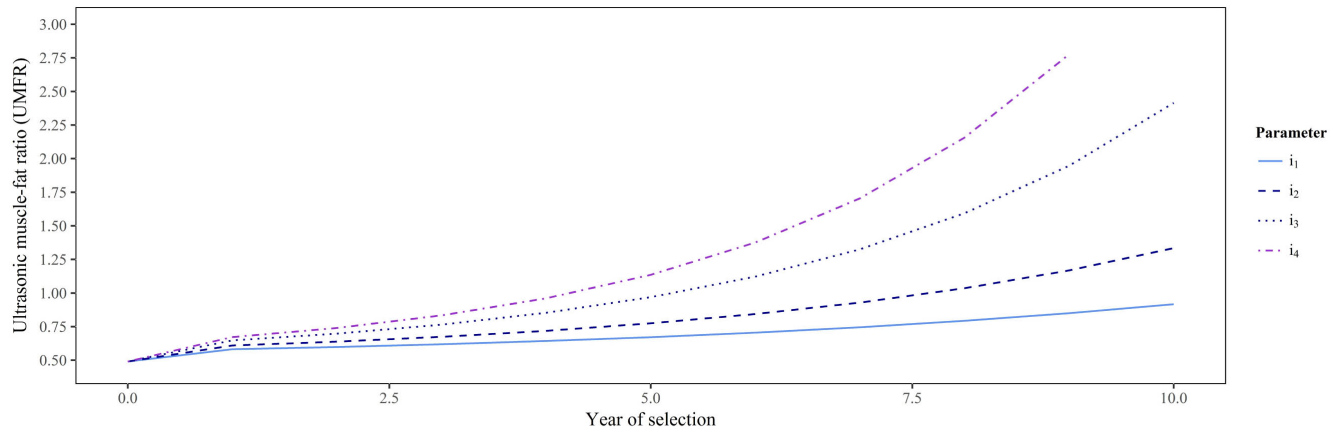

(a)

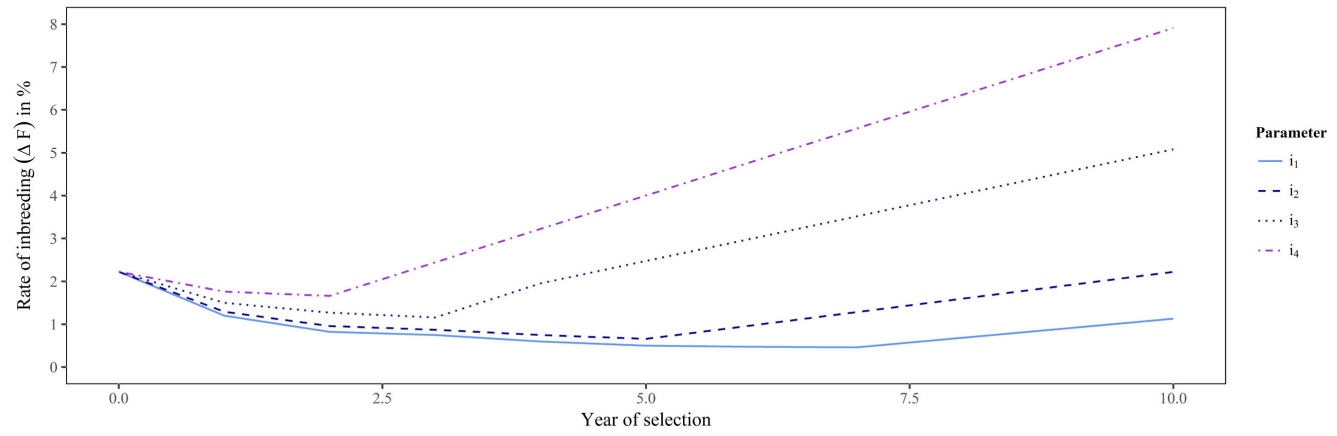

(b)

Figure 5. In (a) Change in genetic gain for ultrasonic muscle-fat ratio (UMFR) and in (b) Corresponding rates of inbreeding $(\Delta F)$ over years with different selection intensities $(i)$. 
and reached values of $0.92,1.34,2.41$, and $>2.75$ for $i_{1}, i_{2}, i_{3}$ and $i_{4}$ after 10 years of selection (Figure $5(\mathrm{a})$ ). Remaining $\Delta F$ increased to values of $1.1 \%, 2.2 \%$, $5.1 \%$, and $7.9 \%$ for $i_{1}, i_{2}, i_{3}$ and $i_{4}$ after 10 years (Figure $5(\mathrm{~b})$ ).

\section{Discussion}

The objective of this study was the identification and implementation of breed-specific traits for a small, local sheep breed. Therefore, phenotypic information from a field experiment were collected and used to estimate novel EBVs. In addition, correlations between these novel and conventional EBVs were investigated and benefits of implementing these novel traits were clarified.

\subsection{Estimation and Correlation of Novel Breeding Values}

The number of reference sires and their tested progeny in the experimental design was small due to the small number of living herd book rams of the GWM breed (Figure 1(a)). The field design depended mainly on the farmers' motivation and conviction regarding this project. Consequently, just a few farmers consented to participate and provide their young rams for the trial. Nevertheless, the reference sire lines were mostly widely selected to achieve genetic variance within the traits but showed still inbreeding and relatedness with each other (Figure 2). The phenotypic information was collected separately for each trait by one person to avoid bias. For the calculation of UMFR, QUS measurements for the muscle and fat depth were measured under predetermined conditions to achieve consistency. In general, repeatability set the upper limit to heritability as a very useful interpretation since the heritability of traits cannot often be obtained and there is a risk of overestimation [24]. For $\mathrm{ADG}_{\mathrm{E}}$, the repeatability and heritability were 0.42 and 0.70 (Table 2). In the studies of María et al. [25], Hassen et al. [26], and Gowane et al. [27], heritability estimated for conventional ADG was low until moderate and varied between 0.15 and 0.26 . It can be assumed that conventional $\mathrm{ADG}$ and $\mathrm{ADG}_{\mathrm{E}}$ are similar traits dependent on feeding as they show the same fixed and random effects. The repeatability and heritability estimated for UMFR were 0.46 and 0.83 (Table 2). Gilmour et al. [28] estimated a heritability for muscle depth and fat depth of between 0.05 and 0.29 . The UMFR can be assumed as a meat-quality trait and these traits exhibits a heritability < 0.18 [29]. Safari et al. [30] provided a heritability for meat-quality traits between 0.05 and 0.18 . Hence, the heritability of $\mathrm{ADG}_{\mathrm{E}}$ and UMFR with 0.70 and 0.83 was obviously over-estimated in this model. The true values for the heritability of these traits are limited by the repeatability of 0.42 for $\mathrm{ADG}_{\mathrm{E}}$ and 0.46 for UMFR. This moderate heritability for both traits was also strengthened by the literature. The genetic correlation between $\mathrm{ADG}_{\mathrm{E}}$ and UMFR of 0.61 (Table 3 ) is probably over-estimated in comparison with the study by Safari et al. [30], where the genetic correlations for live weight and muscle depth and live weight and fat depth were between 0.34 and 0.36 . Strong overestimation of heritability and genetic correlation was due to the small number of animals used in 
the animal model. Probably, some fixed and random effects become significant with an increased number of animals and, hence, heritability may decrease and approximate reality. The high standard error was due to the small number of individuals and limited reference sire lines within the model. Unrelated males and generally animal sizes are often the limiting factors especially in context of local breeds' small populations (Figure 1(a)). Thus, repeatability cannot be ignored in the interpretation of the heritability of these novel traits for the GWM breed. Investigated correlations in Table 4 show, that $\mathrm{ADG}_{\mathrm{I}}$ was positively correlated with MUSC (0.60), whereas $\mathrm{ADG}_{\mathrm{E}}$ was negatively correlated with MUSC (-0.68). This result strengthens the assumption of a biased trait observation regarding $\mathrm{ADG}_{\mathrm{I}}$ and $\mathrm{ADG}_{\mathrm{E}}$, which were negatively $(-0.11)$ but not statistically significant correlated (Table 4). Additionally, the unbiased trait of $\mathrm{ADG}_{\mathrm{E}}$ was positively correlated with the meat-quality trait of UMFR (0.64), which is in accordance with the investigated positive regression and correlation of 0.62 between collected phenotypes for both traits (Figure 3). Hence, a positive impact on meat-quality aspects regarding utilisation of $\mathrm{ADG}_{\mathrm{E}}$ can be assumed.

\subsection{Implementation of Breed-Specific Traits}

The conventional breeding programme of $\mathrm{GWM}$ was geared towards $\mathrm{ADG}_{\mathrm{I}}$, MUSC, and WOL, although the measurement for the trait of $\mathrm{ADG}_{\mathrm{I}}$ is biased and WOL has now become a subsidiary income in Germany. Additionally, the sole trait of MUSC cannot provide any information concerning meat-quality aspects. It is simply an aspect of appearance without any profitability for the breed and shows a strong dependency on $\mathrm{ADG}_{\mathrm{I}}$ (Table 4). Furthermore, the conventional breeding programme focused on biased $\mathrm{ADG}_{\mathrm{I}}$ and, hence, could have led to a reduction in the native genetic variance for the unbiased breed-specific $A_{D} G_{E}$ trait and the loss of this native genetic diversity. The latter can cause long-term degradation of the GWM breed and may discount profitability potentials and competitiveness for the future developments in breed-specific environments. Gandini and Oldenbroek [31] and Meuwissen [3] mentioned that the definition of relevant breeding goals, the improvement of breed genetics, and the enhancement of profitability are the best strategies to move from the conservation to utilisation of a local breed. Such improvements of genetic response were qualified depending on different $i$ in Figure 4 and Figure 5 with special focus on $\Delta F$. Especially in a small, local breed such trait implementations and genetic improvements within a breeding programme have consequences for $\Delta F$ depending on $i$. There exists a link between genetic response and inbreeding (Figure 4 and Figure 5). An increased rate of genetic gain also led to higher rates of inbreeding [32] [33]. In general, inbreeding results in biological risks of genetic variance reduction, inbreeding depression, and accumulation of deleterious alleles [34]. In order to achieve a small population of a local breed with their native genetic diversity and fitness the mating of close relatives and an increased inbreeding should be avoided or restricted. Therefore, a maximum for $\Delta F$ of $1 \%$ per genera- 
tion was predefined from different authors [35] [36], which means a maximum for $\Delta F$ of $0.3 \%$ per annum in case of sheep. For both traits the inbreeding level of the first scenario $i_{1}$ stayed under this threshold of $0.3 \%$ per annum, all other $i$-scenarios had a $\Delta F>0.3 \%$ per annum (Figure 4 (b) and Figure $5(\mathrm{~b})$ ). The differences of $\Delta F$ regarding $i_{1}$ and $i_{2}$ in Figure 4 and Figure 5 were due to different selected reference sires with distinct inbreeding coefficients between both traits. In addition, the whole population of GWM depicts a rapidly increased $\Delta F$ since 2007 (Figure 1(b)) and some selected reference sires exhibits inbreeding and relatedness among each other (Figure 2). Consequently, a p\% of 50 and $i_{1}$ of 0.798 should be chosen for an optimal use of reference sires to achieve genetic response with simultaneously acceptable rates of inbreeding. Nevertheless, with scenario $i_{1}$ genetic response of $481.09 \mathrm{~g} /$ day for $\mathrm{ADG}_{\mathrm{E}}$ and 0.92 for UMFR would be theoretically possible after 10 years of selection (Figure 4(a) and Figure $5(a))$. This implies a trait improvement of $51 \%$ for $A D G_{E}$ and $87 \%$ for UMFR. $\mathrm{ADG}_{\mathrm{I}}$ could be replaced by $\mathrm{ADG}_{\mathrm{E}}$ within the breeding programme in order to achieve the special yield characteristics of the GWM breed. In addition, profitability and competitiveness could be positively influenced compared to conventional sheep breeds in the same environment due to an increased average daily gain based on extensive feed at the dykes. On extensive grassy landscapes, the GWM breed may have higher weight gain by comparison with conventional, intensive mutton breeds (e.g. Texel and German Black-Headed Mutton).With an implemented trait for an unbiased average daily gain, the selection response for the true average daily gain $\left(\mathrm{ADG}_{\mathrm{E}}\right)$ could be processed and improved by breeders and, thus, the competitiveness and genetic gain of this local breed could probably increase. Furthermore, an implementation of $\mathrm{ADG}_{\mathrm{E}}$ would have an impact on meat-quality aspects due to positive correlations between $\mathrm{ADG}_{\mathrm{E}}$ and UMFR (Table 4 and Figure 3). Consequently, a positive selection response can be expected for both traits at the same time while implementing one or the other trait $\left(\mathrm{ADG}_{\mathrm{E}}\right.$ or UMFR) within a breeding programme. This implementation of a meat-quality trait (UMFR) may lead to enhanced profitability and a unique selling position due to the selection response of increased meat quality. However, the implementation of $\mathrm{ADG}_{\mathrm{E}}$ has a negative impact on the conventional trait of MUSC (Table 4). This conventional trait underlies high subjectivity during the live valuation of animals and has no objective data collection. Beyond, MUSC has a strong dependency on $\mathrm{ADG}_{\mathrm{I}}$, as already mentioned. The trait of WOL has no economic value for sheep breeders in Germany. Subsequently, negative consequences for WOL would not sustainably threaten the local GWM breed and might be not fatal for farmers. Additionally, the monetary value for wool from land sheep breeds is minor due to the rough wool fibre.

\section{Conclusion}

The EBVs of $\mathrm{ADG}_{\mathrm{I}}$ and $\mathrm{ADG}_{\mathrm{E}}$ were tendentially negatively correlated, which strengthen the assumption of a biased $\mathrm{ADG}_{\mathrm{I}}$. $\mathrm{ADG}_{\mathrm{E}}$ probably reflects the trait of 
average daily gain objectively and unbiased under normal environmental conditions in case of the GWM breed. Furthermore, the utilization of $\mathrm{ADG}_{\mathrm{E}}$ has a positive impact on meat-quality aspects (UMFR). With the optimal use of reference sires and predefined selection intensity it is possible to achieve genetic response for $\mathrm{ADG}_{\mathrm{E}}$ and UMFR with simultaneously acceptable rates of inbreeding. Implemented novel traits allow selection on breed-specific features, unique native genetic variance, and native genetic diversity. In addition, the profitability may increase due to the selection of these economic and breed-specific traits, which enable increased competitiveness compared to common mutton breeds in the same environment.

\section{Acknowledgements}

Financial support from the ministry of Energy, Agriculture, Environment, Nature, and Digitalization within the framework of the European Innovation Partnership (EIP Agri) is gratefully acknowledged. In addition, the authors give special thanks to the farmers and breeding organization supporting this project faithfully.

\section{Conflicts of Interest}

The authors declare no conflicts of interest regarding the publication of this paper.

\section{References}

[1] Groeneveld, L.F., Lenstra, J.A., Eding, H., Toro, M.A., Scherf, B., Pilling, D., Negrini, R., Finlay, E.K., Jianlin, H., Groeneveld, E., Weigend, S. and The GLOBALDIV Consortium (2010) Genetic Diversity in Farm Animals-A Review. Animal Genetics, 41, 6-31. https://doi.org/10.1111/j.1365-2052.2010.02038.x

[2] Wang, Y., Bennewitz, J. and Wellmann, R. (2017) Novel Optimum Contribution Selection Methods Accounting for Conflicting Objectives in Breeding Programs for Livestock Breeds with Historical Migration. Genetics Selection Evolution, 49, 45. https://doi.org/10.1186/s12711-017-0320-7

[3] Meuwissen, T.H.E. (2009) Genetic Management of Small Populations: A Review. Acta Agriculturae Scandinavica, Section A-Animal Science, 59 71-79. https://doi.org/10.1080/09064700903118148

[4] FAO (2007) The State of the World's Animal Genetic Resources for Food and Agriculture. Rome. www.fao.org/docrep/010/a1250e/a1250e00.html

[5] FAO (2010) Breeding Strategies for Sustainable Management of Animal Genetic Resources. FAO Animal Production and Health Guidelines, No. 3, Rome.

[6] Fernández, J., Meuwissen, T.H.E., Toro, M.A. and Mäki-Tanila, A. (2011) Management of Genetic Diversity in Small Farm Animal Populations. Animal, 5, 1684-1698. https://doi.org/10.1017/S1751731111000930

[7] Boettcher, P.J., Tixier-Boichard, M., Toro, M.A., Simianer, H., Eding, H., Gandini, G., Joost, S., Garcia, D., Colli, L., Ajmone-Marsan, P. and The GLOBALDIV Consortium (2010) Objectives, Criteria and Methods for Using Molecular Genetic Data in Priority Setting for Conservation of Animal Genetic Resources. Animal Genetics, 
41, 64-77. https://doi.org/10.1111/j.1365-2052.2010.02050.x

[8] Meuwissen, T.H.E. (1997) Maximizing the Response of Selection with a Predefined Rate of Inbreeding. Journal of Animal Science, 75, 934-940. https://doi.org/10.2527/1997.754934x

[9] Wellmann, R., Hartwig, S. and Bennewitz, J. (2012) Optimum Contribution Selection for Conserved Populations with Historic Migration. Genetics Selection Evolution, 44, 34. https://doi.org/10.1186/1297-9686-44-34

[10] Sonesson, A.K., Goddard, M.E. and Meuwissen, T.H.E. (2002) The Use of Frozen Semen to Minimize Inbreeding in Small Populations. Genetical Research, 80, 27-30. https://doi.org/10.1017/S0016672302005712

[11] Shepherd, R.K. and Woolliams, J.A. (2004) Minimising Inbreeding in Small Populations by Rotational Mating with Frozen Semen. Genetics Research, 84, 87-93. https://doi.org/10.1017/S0016672304007062

[12] Colleau, J.J. and Avon, L. (2008) Sustainable Long-Term Conservation of Rare Cattle Breeds Using Rotational AI Sires. Genetics Selection Evolution, 40, 415-432. https://doi.org/10.1186/1297-9686-40-4-415

[13] Hospital, F. (2005) Selection in Backcross Programmes. Transactions of the Royal Society B-Biological Sciences, 360, 1503-1511. https://doi.org/10.1098/rstb.2005.1670

[14] Odegard, J., Yazdi, M.H., Sonesson, A.K. and Meuwissen, T.H.E. (2009) Incorporating Desirable Genetic Characteristics from an Inferior into a Superior Population Using Genomic Selection. Genetics, 181, 737-745. https://doi.org/10.1534/genetics.108.098160

[15] Putman, R.J. (1995) Ethical Considerations and Animal Welfare in Ecological Field Studies. Biodiversity and Conservation, 4, 903-915. https://doi.org/10.1007/BF00056197

[16] Wellmann, R. (2018) Optimum Contribution Selection and Population Genetics. https://cran.r-project.org/web/packages/optiSel/optiSel.pdf

[17] Lewis, R.M. and Simm, G. (2000) Selection Strategies in Sire Referencing Schemes in Sheep. Livestock Production Science, 67, 129-141. https://doi.org/10.1016/S0301-6226(00)00182-2

[18] Butler, D.G., Cullis, B.R., Gilmour, A.R. and Gogel, B.J. (2009) ASReml-R Reference Manual. Department of Agriculture, Fisheries and Forestry.

[19] Brien, C. (2016) asremlPlus: Augments the Use of "ASReml-R" in Fitting Mixed Models. R Package Version 2.0-12. https://cran.r-project.org/web/packages/asremlPlus/asremlPlus.pdf

[20] Lessells, C.M. and Boag, P.T. (1987) Unrepeatable Repeatabilities: A Common Mistake. Auk, 104, 116-121. https://doi.org/10.2307/4087240

[21] Falconer, D.S. and Mackay, T.F.C. (1996) Introduction to Quantitative Genetics. Longman House, Essex.

[22] R Core Team (2018) R: A Language and Environment for Statistical Computing. R Foundation for Statistical Computing, Vienna. https://www.R-project.org

[23] Rendel, J.M. and Robertson, A. (1950) Estimation of Genetic Gain in Milk Yield by Selection in a Closed Herd of Diary Cattle. Journal of Genetics, 50, 1-8. https://doi.org/10.1007/BF02986789

[24] Dohm, M.R. (2002) Repeatability Estimates Do Not Always Set an Upper Limit to Heritability. Functional Ecology, 16, 273-280. 
https://doi.org/10.1046/j.1365-2435.2002.00621.x

[25] María, G.A., Boldman, K.G. and Van Vleck, L.D. (1993) Estimates of Variances Due to Direct and Maternal Effects for Growth Traits of Romanov Sheep. Journal of Animal Science, 71, 845-849. https://doi.org/10.2527/1993.714845x

[26] Hassen, Y., Fuerst-Waltl, B. and Sölkner, S. (2003) Genetic Parameter Estimates for Birth Weight, Weaning Weight and Average Daily Gain in Pure and Crossbred Sheep in Ethiopia. Journal of Animal Breeding and Genetics, 120, 29-38. https://doi.org/10.1046/j.1439-0388.2003.00361.x

[27] Gowane, G.R., Prince, L.L.L., Lopes, F.B., Paswan, C. and Sharma, R.C. (2015) Genetic and Phenotypic Parameter Estimates of Live Weight and Daily Gain Traits in Malpura Sheep Using Bayesian Approach. Small Ruminant Research, 128, 10-18. https://doi.org/10.1016/j.smallrumres.2015.04.016

[28] Gilmour, A.R., Luff, A.F., Fogarty, N.M. and Banks, R. (1994) Genetic Parameters for Ultrasound Fat Depth and Eye Muscle Measurements in Live Poll Dorset Sheep. Australian Journal of Agricultural Research, 45, 1281-1291. https://doi.org/10.1071/AR9941281

[29] Larsgard, A.G. and Olesen, I. (1998) Genetic Parameters for Direct and Maternal Effects on Weights and Ultrasonic Muscle and Fat Depth of Lambs. Livestock Production Science, 55, 273-278. https://doi.org/10.1016/S0301-6226(98)00134-1

[30] Safari, E., Fogarty, N.M. and Gilmour, A.R. (2005) A Review of Genetic Parameter estimates for Wool, Growth, Meat and Reproduction Traits in Sheep. Livestock Production Science, 92, 271-289. https://doi.org/10.1016/j.livprodsci.2004.09.003

[31] Gandini, G. and Oldenbroek, K. (2007) Strategies for Moving from Conservation to Utilisation. In: Oldenbroek, K., Ed., Utilisation and Conservation of Farm Animal Genetic Resources, Wageningen Academic Publishers, Wageningen, 29-54.

[32] Toro, M.A., Silió, L. and Woolliams, J.A. (1990) Selection for Lean Meat Production in Sheep: A Simulation Study. Proceedings 4th World Congress on Genetics Applied to Livestock Production, Vol. 15, Edinburgh, 23-27 July 1990, 96-99.

[33] Villanueva, B., Simm, G. and Woolliams, J.A. (1995) Genetic Progress and Inbreeding for Alternative Nucleus Schemes for Beef Cattle. Animal Science, 61, 231-239. https://doi.org/10.1017/S1357729800013758

[34] Villanueva, B., Bijma, P. and Woolliams, J.A. (2000) Optimal Mass Selection Policies for Schemes with Overlapping Generations and Restricted Inbreeding. Genetics Selection Evolution, 32, 339-355. https://doi.org/10.1186/1297-9686-32-4-339

[35] Meuwissen, T.H.E. and Sonesson, A.K. (2004) Genotype-Assisted Optimum Contribution Selection to Maximize Selection Response over a Specified Time Period. Genetics Research, 84, 109-116. https://doi.org/10.1017/S0016672304007050

[36] Nielsen, H.M., Sonesson, A.K. and Meuwissen, T.H.E. (2014) Optimum Contribution Selection Using Traditional Best Linear Unbiased Prediction and Genomic Breeding Values in Aquaculture Breeding Schemes. Journal of Animal Science, 89, 630-638. https://doi.org/10.2527/jas.2009-2731 